\title{
An ultrastructural study of the digestive tract of Saccostrea palmula, (Carpenter, 1857).
}

Silva-Olivares, Angélica*; Ortíz, Esperanza**; Uría, Esther-k*; Tsutsumi, Victor*; Shibayama, Mineko*. Departamento de Patologia Experimental, Cinvestav-IPN. México*. Departamento de Morfología. Escuela Nacional de Ciencias Biológicas, IPN. México*k*. angelica0517@yahoo.commx

Saccastrea palmula (oyster mangrove) is an important biological species. This oyster is distributed from Laguna San Ignacio, Baja California, México to Panama and Galapagos Islands, Ecuador. The studies on the shell, the sott tissues as well as the ecology inherent to each species, constitute solid bases for their knowledge and taxonomic definition One of the main characteristics that express a significant adaptation at genus and species levels constitute the anatomic description of the digestive systems. Presently, the exact taxonomic position of this species, which belongs to ostreidae family is unclear. For better understanding the taxonomy, biology and ecology of this mollusk, we analyzed the ultrastructure of the digestive system The oysters were collected from San Carlos Port; Magdalena Bay in Baja California Sur, México. The shells were opened and 2 mm sections were taken from different parts of the gut (palps, mouth and esophage). Fixed in $2.5 \%$ glutaraldehyde in seawater, $\mathrm{pH} 8.0$, post-fixed in $1 \%$ osmium tetroxide and processed for electron microscope. Fine sections were stained with uranyl acetate and lead citrate, and observed in a Zeiss EM-10 transmission electron microscope. Our results showed that the ep thelium of palps, mouth and esophage was ciliated columnar squamous epithelium, with microvilli. Cell junctions of adherens and occludens types were presert between the epthelial cells of this species. Our results show that the digestion process in Saccostrea palmula starts in the palps. Abundant mitochondria in the ap ical zones of the ep ithelial cells of the palps were observed; contrarily, mitochondria at ep ithelium of mouth and esop hage mucosa were mainly localized at the basal invaginations of the cellular merrbrane that are associated with cellular energetic processes. Epithelial cells from esophage contained lysosomes that are associated with digestion, cell absorption and enzymatic activities. In sum, an important difference observed in this species is that the digestive process is initiated at the palps level contrarily to most reports in this genus that consider that the digestion starts at the stomach

1. Castillo, R Z G. García, C. A 1986. Taxonomía y Anatomía Comparada de las Ostras de las Costas de México. An Inst. Cienc. del Mar y Limnol. Univ. Nal Autón México, 13 (2) : $249-314$

2. Harry, H E 1981. Newly discovered anatomical characters useful in clasifyng Osters (Ostreacea, Gryphaeidae and Ostreidae). Abstract Am Malacol. Union, Bull. for 1981. (2) 34 

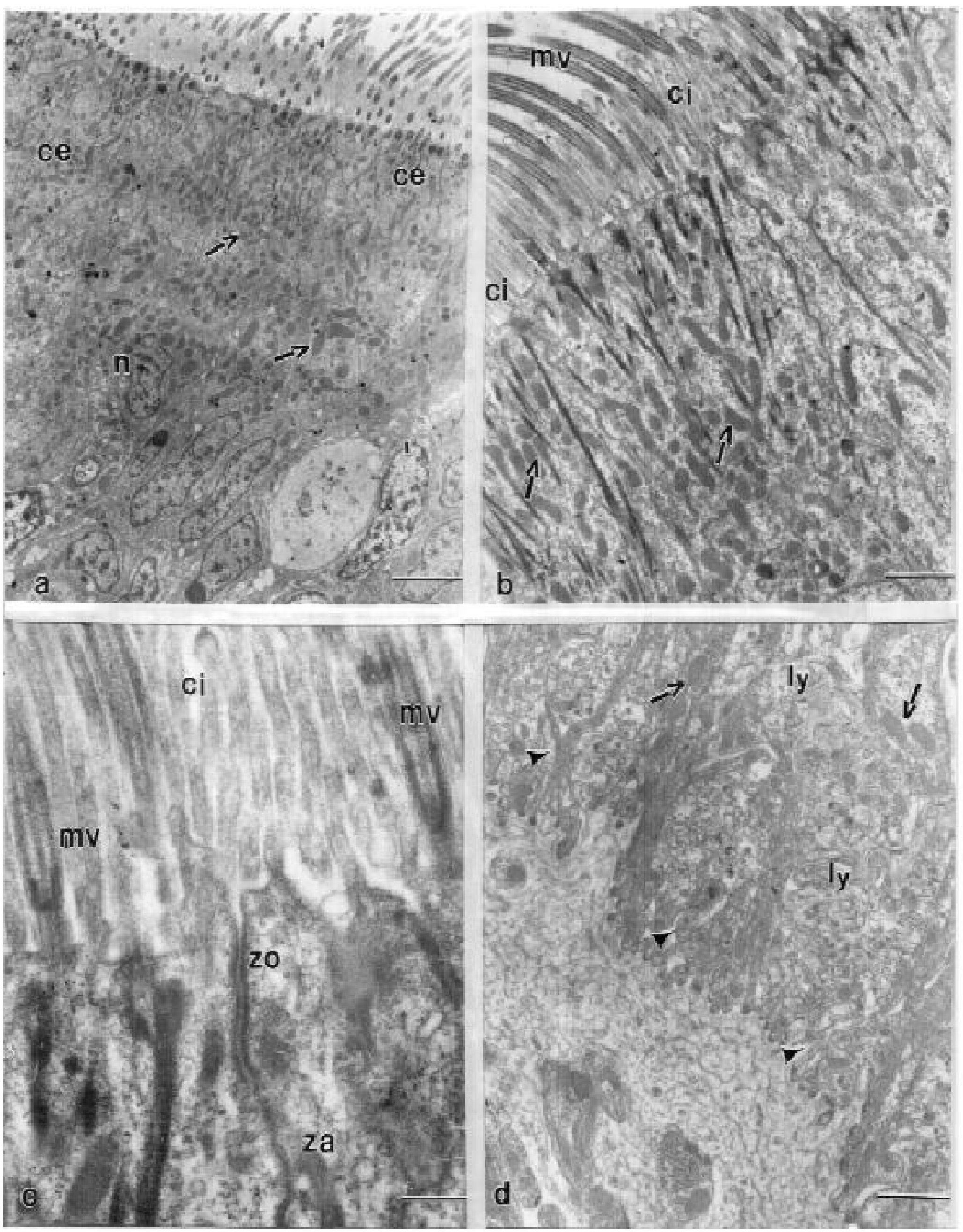

Fig. 1 (a) Saccostrea paluma. Palpe, ciliated columnar squarnus epithelium (ce), nuclei (n) and abundant mitochondria (arrows) are shown. Barr $=1 \mu \mathrm{m}$. (b) Mouth, microvilli (mv), cilium (ci) and mitochondrias (arrows) are shown in the epithelium. Barr = $1 \mu \mathrm{m}$. (c) Mouth, cilium (ci), microvilli (mv), zonula occludens (zo), zonula adherens (za) are present. Barr $=0.5 \mu \mathrm{m}$. (d) Esophage, sec undary lysosomes (ly), mitochondria (arrows) and invaginations of the basal membrane projecting into the cytoplasm (arrow-head) are observed in the basal portion of the epithe lial cells. Barr $=1 \mu \mathrm{m}$. 